\title{
Non-persistence and non-adherence to MTX therapy in patients with rheumatoid arthritis: a retrospective cohort study based on German RA patients
}

\author{
This article was published in the following Dove Press journal: \\ Patient Preference and Adherence \\ 20 July 2017 \\ Number of times this article has been viewed
}

\author{
Sabrina Müller' \\ Thomas Wilke' \\ Andreas Fuchs ${ }^{2}$ \\ Ulf Maywald ${ }^{2}$ \\ Jan-Paul Flacke ${ }^{3}$ \\ Harald Heinisch ${ }^{4}$ \\ Klaus Krüger ${ }^{5}$ \\ Institute for Pharmacoeconomics \\ and Medication Logistics, University \\ of Wismar, Wismar, ${ }^{2}$ AOK PLUS, \\ Dresden, ${ }^{3}$ Roche Pharma AG, \\ Grenzach-Wyhlen, ${ }^{4}$ Chugai \\ Pharma Europe Ltd, Frankfurt/M, \\ ${ }^{5}$ Praxiszentrum St Bonifatius, Munich, \\ Germany
}

Objective: This study aimed to assess the level of nonpersistence (NP) and nonadherence (NA) to methotrexate (MTX) therapy in German patients with rheumatoid arthritis (RA).

Materials and methods: Based on German claims data, RA patients who received a MTX therapy (subgroup: treatment-naive patients) were analyzed. NP was defined as treatment gap $>12$ weeks. Regarding NA, it is the overall medication possession ratio (MPR) during an observational period of 12 or 24 months after therapy, and the MPR is calculated only for the periods of therapy continuation; NA was defined as MPR $<80 \%$.

Results: A total of 7,146 RA patients who received at least one MTX prescription (subgroup: 1,211 treatment-naive patients) could be observed (mean age: 64.4 years, $73.6 \%$ female). Percentage of NP patients among MTX-naive patients after 6, 12 and 18 months was $16.7 \%$, $34.0 \%$ and $36.7 \%$, respectively. After MTX therapy discontinuation, 39.9\% had restarted their MTX therapy, $13.8 \%$ had received another non-MTX synthetic disease-modifying antirheumatic drug (sDMARD), 8.1\% had biological DMARD (bDMARD) and 49.2\% had not received any DMARD prescription at all. Overall, 12- and 24-month MPRs for MTX therapy were 83.0\% and $76.5 \%$ with a percentage of NA patients of $25.8 \%$ and $33.8 \%$, respectively. During periods of general treatment continuation, the percentage of patients with an MPR $<80 \%$ was $6.5 \%$.

Conclusion: NP to MTX treatment seems to be common in one-fourth of German patients with RA. An additional number of patients, at least $6.5 \%$, are also affected by NA. A considerable percentage of RA patients who discontinued MTX therapy do not receive any follow-up DMARD therapy.

Keywords: rheumatoid arthritis, RA, MTX therapy, adherence to MTX therapy, persistence with MTX therapy, discontinuation of MTX therapy

\section{Introduction}

Rheumatoid arthritis (RA) is a chronic systemic autoimmune inflammatory disease with a prevalence of up to $1 \%$ in western countries. ${ }^{1,2}$ Poorly controlled RA results in severe progressive joint damage, functional disability, morbidity, poor health-related quality of life and higher mortality. ${ }^{3,4}$

According to current treatment guidelines, methotrexate (MTX) as a synthetic disease-modifying antirheumatic drug (sDMARD) is the appropriate first-line agent (in combination with glucocorticoids) for the majority of RA patients as part of a treat-to-target approach. ${ }^{5}$ If MTX therapy fails to improve symptoms after 3 months or fails to reach treatment targets after 6 months, it is recommended to move to another
Correspondence: Sabrina Müller Institute for Pharmacoeconomics and Medication Logistics, University of Wismar, Alter Holzhafen 19, 23966 Wismar, Germany

Tel +49384I 7581014

Fax +49 384I 758 I0II

Email kontakt@ipam-wismar.de 
SDMARD, another SDMARD combination or to add a biological DMARD (bDMARD).

When taken as prescribed, SDMARD and bDMARD therapy can result in remission of RA disease activity. ${ }^{5}$ However, nonadherence (NA), defined as poor implementation of a generally continued therapy, and nonpersistence (NP), defined as general discontinuation of therapy, have been reported to be major challenges in the real-world treatment of RA patients. ${ }^{6}$ Although bDMARD therapy is currently used in the treatment of a minority of RA patients, ${ }^{7}$ more is known about persistence with/adherence to bDMARD therapy than persistence with/adherence to first-line sDMARD and, specifically, MTX therapy. ${ }^{8-10}$ Furthermore, existing studies addressing NA or NP associated with MTX therapy in RA patients failed to differentiate between persistence and adherence. ${ }^{6,11}$

Consequently, the main objectives of this study were to assess the level of NP and NA in German patients with RA and to describe the DMARD treatment of MTX discontinuers.

\section{Materials and methods}

\section{Data source and patient sample}

We did a retrospective noninterventional cohort analysis based on anonymized claims data provided by a German statutory health care fund (AOK PLUS; 2.8 million insured) for the years 2010-2013. The analysis included all RA patients permanently enrolled in the database from January 01, 2010, until the end of the observational period; death during the observational period was the only exception to the undisrupted enrollment requirement. A patient was defined as RA patient if at least one outpatient RA-ICD-10 diagnosis (ICD-10 M05: seropositive RA; M06: other RA; excluding M06.1: adult-onset still disease) and/or at least one inpatient RA-ICD-10 diagnosis was documented prior to the first observed reference prescription of study medication.

\section{Observational periods}

We analyzed persistence with/adherence to MTX therapy in common use (Anatomical-Therapeutic-Chemical [ATC] codes M01CX01/L04AX03). Analyses were carried out in all patients receiving MTX therapy, defined as at least one observed MTX prescription from January 01, 2010 to December 31, 2011, with a potential follow-up period of 24 months. Analyses also included a subgroup of MTX treatment-naive patients, defined as no MTX prescription in the 12 months prior to the first observed MTX prescription in the period between January 01, 2011 and December 31, 2011. Reference period, inclusion period, index date and follow-up period are explained in Figure 1. In all the analyses, patients who received any MTX therapy as intravenous infusion therapy were excluded, because no reliable assumptions could be made regarding the prescribed daily dosage (PDD).

\section{Assessment of treatment persistence}

Persistence with MTX treatment was reported for the following groups: all treatment-naive patients and, as subgroups, MTX treatment-naive patients who received 1) MTX monotherapy only (no concomitant treatment with other DMARD agents until the end of the follow-up period or the first observed treatment gap, whichever came first), 2) a combination therapy of MTX and other sDMARDs (sDMARD agents: leflunomide/ciclosporin/azathioprine/sodium aurothiomalate/sulfasalazin/metronidazole/tinidazole; ATC codes: L04AA13/L04AD01/L04AX01/M01CB01/ M01CX02/P01BA01/P01BA02), 3) a combination therapy of MTX and bDMARDs (bDMARD agents: anakinra/ tocilizumab/abatacept/adalimumab/certolizumab/etanercept/ golimumab/infliximab; ATC codes: L04AC03/L04AC07/ L04AA24/L04AB04/L04AB05/L04AB01/L04AB06/ L04AB02), 4) oral MTX therapy only (with and without concomitant DMARD/bDMARD medication), 5) subcutaneous MTX therapy only (with and without concomitant DMARD/ bDMARD medication) and finally 6) a change of application mode from subcutaneous to oral MTX therapy or vice versa (with and without concomitant DMARD/bDMARD medication) during the follow-up period. We allowed for any previous non-MTX medication and any concomitant medication during MTX therapy.

Our analysis was based on the number of days covered by observed prescriptions recorded in the database. Because data on PDD were missing, which is common in most known claims datasets, we developed and validated a model providing assumptions for PDD. This model was developed for 12 different strengths and three different pack sizes per strength for MTX therapy as available in the German pharmaceutical market.

We assumed the following: the PDD associated with an MTX prescription was assumed to be equal to one tablet/ subcutaneous injection a week. Stockpiling was included by assuming that, in case there were overlapping medications, the previous supply was taken fully before the new supply was initiated. Additionally, hospitalization periods were excluded from observed days because drug supply during hospitalization was assumed to be arranged by hospitals.

However, in case a change in the application mode was observed (from oral to subcutaneous or vice versa), we assumed that stock of the previous prescription would no longer be used. Furthermore, we applied two additional 


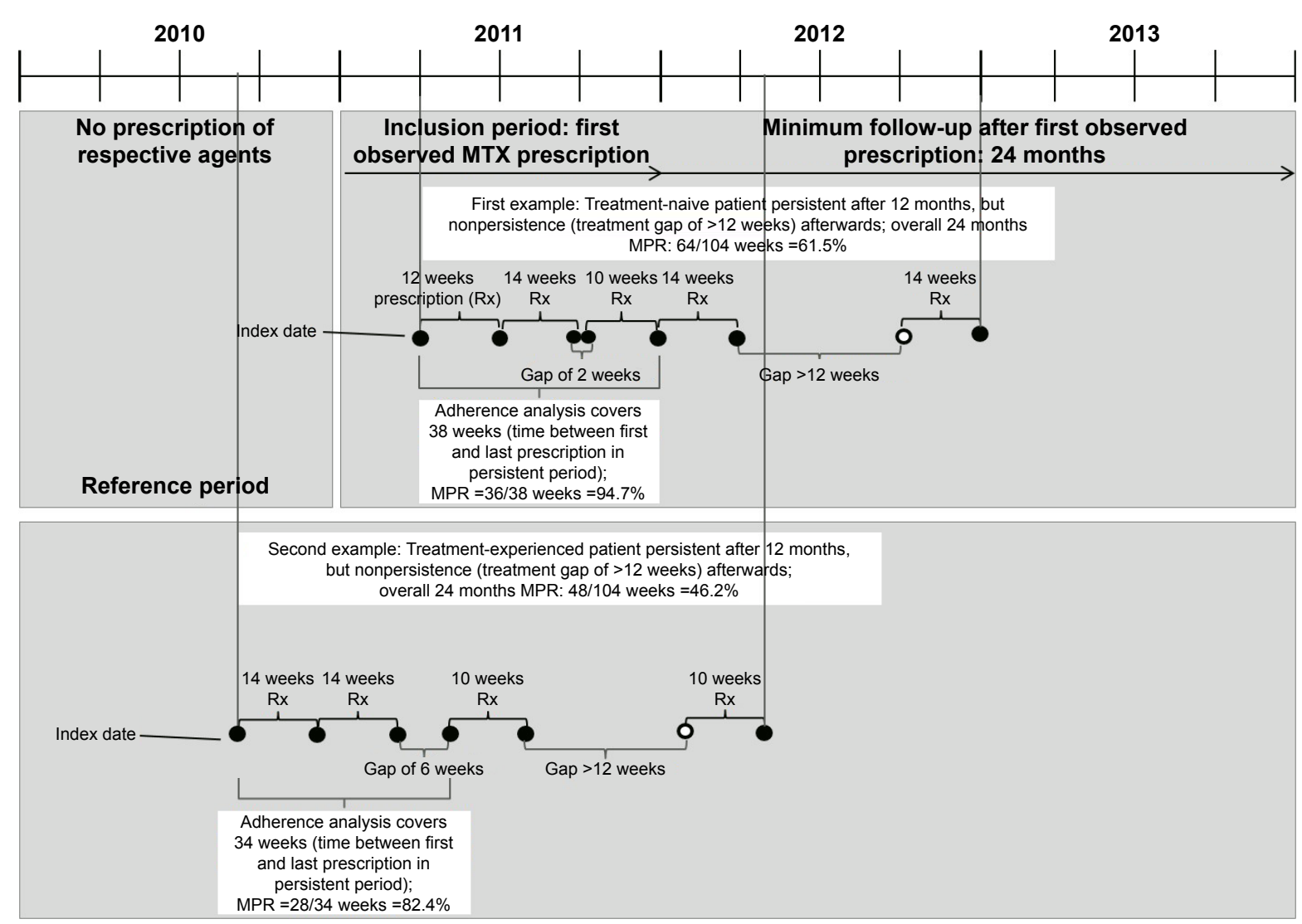

Figure I Methodology of analysis.

Note: The figure defines reference period, index date and observational period and shows that main treatment adherence analysis was carried out for periods of therapy continuation only.

Abbreviations: MTX, methotrexate; MPR, medication possession ratio.

assumptions. First, in case the dosage strength of a second prescribed MTX package was different from the previous one (ie, $2.5 \mathrm{mg}$ instead of $10 \mathrm{mg}$ ), we observed the third follow-up prescription. If that included the dosage of the first observed prescription again (ie, $10 \mathrm{mg}$ ) or a dosage resulting from the sum of both previous prescribed dosages (ie, $12.5 \mathrm{mg}$ ), we assumed the second one to be an add-on dosage to the first prescribed dosage, leading to a PDD, which was the sum of both first prescriptions (ie, $12.5 \mathrm{mg} / \mathrm{wk}$ ). However, if the third prescription included the same strength as the second prescription (ie, third prescription with $2.5 \mathrm{mg} / \mathrm{wk}$ again), we assumed that there was a change in prescribed PDD (ie, $2.5 \mathrm{mg} / \mathrm{wk})$.

Second, we calculated on a continuous basis the resulting medication possession ratios (MPRs) for three subsequent MTX prescriptions. If the resulting MPR was $>200 \%$, we assumed the PDD to be twice as high as the originally assumed PDD for the period covered by these three prescriptions for the respective period.

It should be noted that the PDD was reassessed with each observed MTX prescription. Both abovementioned specific assumptions consequently might have led to revised PDDs, but this only applied to a period from the currently observed prescription until the next one. With the day of the follow-up prescription, a new assessment of the PDD including both assumptions was done.

The developed PDD model as outlined previously was subsequently validated in a separate validation study. Based on a medical chart review, five study sites documented 934 MTX prescriptions and the associated, physician-based PDDs of 160 RA patients (inclusion criteria: age above 18 years, confirmed RA diagnosis and current/previous treatment with MTX for at least 24 months), using predefined case report forms. Specifically, we asked study sites to document all MTX prescriptions (including prescription date, application mode, dosage strength, package size and recommended dosage) of the last 2 years for each patient. Based on these documentations, we calculated the overall MPR between the first and the last documented MTX prescriptions, as defined subsequently (ratio of the supplied days and the duration between the first and the last documented prescriptions). The percentage of patients with an MPR $<80 \%$ based on rheumatologists' data was compared with the percentage of patients with MPR $<80 \%$ based on different PDD models 
as used in the main claims-based data analysis (Table 1). The PDD model with the lowest deviation between rheumatologists' records and our PDD assumptions was used as base case in the full claims data analysis; it was the model described previously.

NP was defined as a treatment gap of $>12$ weeks in the base case; in a sensitivity analysis, we also used 24 weeks as threshold. Persistence was reported based on Kaplan-Meier (KM) curves and the percentage of patients who could be classified as NP at 6, 12 and 18 months after therapy start (index date). Furthermore, we reported the average treatment continuation time for the entire period of 18 months and time until MTX treatment discontinuation for patients who discontinued MTX therapy after 6,12 and 18 months.

\section{Assessment of postdiscontinuation treatment}

In our base case scenario (12-week gap, NP assessment 18 months after index date), we reported whether patients who discontinued MTX treatment received any follow-up DMARD treatment during 12 months after treatment discontinuation and, if applicable, which treatment they received. Patients who could not be observed for a 12-month follow-up after an NP event were excluded from this analysis.

\section{Assessment of treatment adherence}

Treatment adherence was analyzed in two ways. First, for the overall sample, including those patients who may have discontinued therapy during the follow-up period and those continuing their therapy, we analyzed the overall MPR for both 1 and 2 years based on the following formula:

$\operatorname{MPR}=$

Number of days supply received during observational period

(365 OR 730 days - hospitalization days - days after death)

Table I Applied PDD models: results of the validation study

\begin{tabular}{|c|c|c|c|c|c|}
\hline Model assumptions & $\begin{array}{l}\text { Base case } \\
\text { scenario }\end{array}$ & Scenario I & Scenario 2 & Scenario 3 & Scenario 4 \\
\hline $\begin{array}{l}\text { PDD assumed to be equal to one pill/one } \\
\text { injection per week }\end{array}$ & Included & Included & Included & Included & $\begin{array}{l}\text { Not included - } \\
\text { DDD was used }\end{array}$ \\
\hline $\begin{array}{l}\text { Hospitalization periods taken out from } \\
\text { observation }\end{array}$ & Yes & Yes & Yes & Yes & Yes \\
\hline $\begin{array}{l}\text { Stockpiling if no change of application } \\
\text { mode was observed }\end{array}$ & Included & Included & Included & Included & Included \\
\hline $\begin{array}{l}\text { Consideration of possible dosage strength } \\
\text { combination (eg, one pill of } 10 \mathrm{mg} \text { and } \\
\text { one pill of } 2.5 \mathrm{mg} \text { for a prescribed dosage } \\
\text { of } 12.5 \mathrm{mg} / \mathrm{wk} \text { ) }\end{array}$ & Included & Included & $\begin{array}{l}\text { Not } \\
\text { included }\end{array}$ & $\begin{array}{l}\text { Not } \\
\text { included }\end{array}$ & Not included \\
\hline $\begin{array}{l}\text { PDD assumed to be } 200 \% \text { of the } \\
\text { originally assumed PDD if the } \\
\text { continuously calculated MPR for three } \\
\text { subsequent prescriptions was }>200 \%\end{array}$ & Included & $\begin{array}{l}\text { Not } \\
\text { included }\end{array}$ & Included & $\begin{array}{l}\text { Not } \\
\text { included }\end{array}$ & Not included \\
\hline $\begin{array}{l}\text { Mean MPR for } 160 \text { RA validation study } \\
\text { patients based on above model }\end{array}$ & 85.78 & 85.82 & 86.30 & 86.35 & 66.09 \\
\hline $\begin{array}{l}\text { Mean MPR for I } 60 \text { RA validation study } \\
\text { patients based on reported PDD by } \\
\text { rheumatologists }\end{array}$ & $82.11 \%$ & & & & \\
\hline $\begin{array}{l}\text { Deviation in MPR between PDD model } \\
\text { and reported PDD by rheumatologists } \\
\text { (percentage points) }\end{array}$ & +3.66 & +3.71 & +4.19 & +4.24 & -16.02 \\
\hline $\begin{array}{l}\text { Percentage of RA validation study patients } \\
\text { with MPR }<80 \% \text { based on above model }\end{array}$ & 26.88 & 26.88 & 26.25 & 26.25 & 73.13 \\
\hline $\begin{array}{l}\text { Percentage of RA validation study patients } \\
\text { with MPR }<80 \% \text { based on PDD reported } \\
\text { by rheumatologists }\end{array}$ & 35.63 & & & & \\
\hline $\begin{array}{l}\text { Deviation in percentage of RA patients } \\
\text { between PDD model and reported PDD } \\
\text { by rheumatologists (percentage points) }\end{array}$ & -8.75 & -8.75 & -9.38 & -9.38 & +37.50 \\
\hline
\end{tabular}

Note: aPDD assumed to be equal to the DDD (as defined by WHO) of the last prescription.

Abbreviations: PDD, prescribed daily dosage; DDD, defined daily dosage; MPR, medication possession ratio; RA, rheumatoid arthritis. 
In our second NA analysis, we explored adherence only for the period in which a patient continued MTX therapy (no treatment gap $>12$ weeks). If a treatment gap of $>12$ weeks was observed, the observational period for this specific patient lasted only from index date until the day of the last prescription before the first treatment gap $>12$ weeks was observed (Figure 1):

\section{$\mathrm{MPR}=$ \\ Number of days supply received during persistent period}

(Days between first and last prescription without any treatment gaps $>12$ weeks - hospitalization days)

Adherence was reported for all RA patients who received MTX treatment and, as subgroups, MTX treatment-naive patients, patients who received MTX monotherapy, oral MTX therapy or subcutaneous MTX therapy or who experienced a switch in application form.

Adherence was reported in the following three ways:

1. as mean/median MPR,

2. as the percentage of patients with MPR $<80 \%$,

3. in a sensitivity analysis, as the percentage of patients with MPR $<70 /<90 \%$.

In case an MPR was above $100 \%$, it was truncated to $100 \%$.

\section{Statistical analysis}

Significance of differences between discontinuation rates as shown by KM curves was tested by means of log-rank tests. Significant level was set at $P<0.05$, and all reported $P$-values were two sided. Descriptive evaluations were executed with Microsoft SQL Server 2008 and Microsoft Excel 2010. All other statistical analyses were performed with STATA 13.1.

\section{Ethics and scientific approval}

This was a noninterventional, retrospective study analyzing anonymized data as defined by section 3 (6) of the Federal Data Protection Act. ${ }^{12}$ For the first part of the study, which was a medical chart review and for the subsequent secondary data analysis of claims data, anonymized data were only used. Thus, ethical approval and informed consent from patients were not obtained. This is in accordance with national guidelines and recommendations, ${ }^{13,14}$ the Federal Data Protection Act (the use of anonymized data is not restricted by means of data protection regulations) $)^{12}$ and with the policy of the institutions conducting the analysis (IPAM and AOK PLUS).
However, the study was evaluated by a scientific steering committee to which all the authors belonged.

\section{Results \\ MTX-experienced and MTX-naive RA samples}

In our sample, 7,146 RA patients who received at least one MTX prescription in 2010 or 2011 (mean age: 64.4 years, $73.6 \%$ female) were observed. Of these, 1,211 started MTX treatment in 2011 (mean age: 62.2 years, 71.5\% female). Patient characteristics are listed in Table 2.

For MTX-experienced and MTX-naive patients, percentages of patients who received MTX monotherapy (no concomitant sDMARD/bDMARD therapy) were $79.3 \%$ and $83.7 \%$, respectively. Percentages of RA patients who received an MTX+sDMARD combination therapy (without any bDMARD) were $10.4 \%$ and $9.7 \%$, and percentages of RA patients who received at least one bDMARD prescription during follow-up were $10.3 \%$ and $6.6 \%$, respectively. In all, $71.5 \%$ and $71.1 \%$ of MTX-experienced and MTX treatmentnaive patients received oral MTX therapy only, $18.5 \%$ and $16.9 \%$ received subcutaneous MTX therapy only and $10.0 \%$ and $12.0 \%$ switched between application modes during the follow-up period.

\section{Assessment of treatment persistence}

The results of the MTX treatment persistence analysis based on 1,211 RA patients who started MTX treatment are presented in Figure 2A and B and Table 3. Based on a $>12$-week treatment gap definition, percentages of NP patients after 6, 12 and 18 months were $16.7 \%, 34.0 \%$ and $36.7 \%$, respectively. Mean time until discontinuation was $11.9,22.2$ and 25.2 weeks, respectively. The estimated mean overall time on treatment within the 18-month follow-up period was 58.4 weeks. Based on all patients showing NP after 6 months, $42.4 \%$ received a single MTX-index prescription (early NP).

If patients receiving MTX monotherapy were compared with patients receiving a combination therapy of MTX and other sDMARDs/bDMARDs, persistence was not significantly different (Figure 2A). Additionally, persistence rates did not differ between different types of application modes (Figure 2B). A change in application was associated with a higher treatment continuation rate. However, since a switch itself is associated with at least two different MTX prescriptions, this obviously excluded all NP patients with only one prescription from this group. 
Table 2 Characteristics of observed RA patients used for persistence and adherence analysis

\begin{tabular}{|c|c|c|}
\hline Characteristics (baseline period 2010) & $\begin{array}{l}\text { RA-prevalent patients who } \\
\text { received at least one MTX } \\
\text { prescription in January } 0 \mathrm{I} \text {, } \\
2010 \text { to December } 3 \mathrm{I}, 20 \mathrm{I}\end{array}$ & $\begin{array}{l}\text { RA-prevalent patients } \\
\text { who started MTX } \\
\text { therapy (first MTX } \\
\text { prescription in 20II) }\end{array}$ \\
\hline $\mathrm{N}$ & 7,146 & $1,21 \mathrm{I}$ \\
\hline Mean age, years (SD) & $64.4(12.7)$ & $62.2(12.3)$ \\
\hline Percentage of female patients & 73.6 & 71.5 \\
\hline Mean CCl without age factor, based on 2010 (SD) & $2.60(2.03)$ & $2.13(2.06)$ \\
\hline $\begin{array}{l}\text { Mean number of chronic medications (at least two } \\
\text { prescriptions of specified ATC groups) in } 2010 \text { (SD) }\end{array}$ & $5.15(3.43)$ & $4.27(3.4 I)$ \\
\hline $\begin{array}{l}\text { Mean number of all-cause inpatient hospitalizations } \\
\text { in } 2010 \text { (SD) }\end{array}$ & $0.58(1.09)$ & $0.54(1.10)$ \\
\hline $\begin{array}{l}\text { Mean number of outpatient visits associated with } \\
\text { RA in } 2010 \text { (SD) }\end{array}$ & $6.50(3.78)$ & $2.86(3.58)$ \\
\hline $\begin{array}{l}\text { Percentage of patients who visited a rheumatologist } \\
\text { (at least once) in } 2010\end{array}$ & 56.5 & 56.7 \\
\hline $\begin{array}{l}\text { Percentage of patients who received oral MTX } \\
\text { therapy during follow-up period ( } 24 \text { months or until } \\
\text { death) only }\end{array}$ & 71.5 & 71.1 \\
\hline $\begin{array}{l}\text { Percentage of patients who received subcutaneous } \\
\text { MTX therapy during follow-up period ( } 24 \text { months } \\
\text { or until death) only }\end{array}$ & 18.5 & 16.9 \\
\hline $\begin{array}{l}\text { Percentage of patients who received both an oral } \\
\text { and a subcutaneous MTX therapy during follow-up } \\
\text { period ( } 24 \text { months or until death) }\end{array}$ & 10.0 & 12.0 \\
\hline $\begin{array}{l}\text { Percentage of patients who received MTX } \\
\text { monotherapy during follow-up period ( } 24 \text { months } \\
\text { or until death) })^{\mathrm{a}}\end{array}$ & 79.3 & 83.7 \\
\hline $\begin{array}{l}\text { Percentage of patients who received MTX plus } \\
\text { other DMARD combination therapy during follow- } \\
\text { up period ( } 24 \text { months or until death) }\end{array}$ & 10.4 & 9.7 \\
\hline $\begin{array}{l}\text { Percentage of patients who received MTX plus } \\
\text { bDMARD combination therapy during follow-up } \\
\text { period ( } 24 \text { months or until death) })^{\mathrm{a}}\end{array}$ & 10.3 & 6.6 \\
\hline
\end{tabular}

Notes: alf a patient filled at least one prescription of a bDMARD during the observational period, he or she was assigned to the MTX+bDMARD group. If this was not the case but the patient filled at least one prescription of an sDMARD, he or she was assigned to the MTX+sDMARD group. In case a patient received MTX prescriptions only, he or she was assigned to the MTX monotherapy group.

Abbreviations: RA, rheumatoid arthritis; MTX, methotrexate; $\mathrm{CCl}$, Charlson comorbidity index; ATC, Anatomical-Therapeutic-Chemical; DMARD, disease-modifying antirheumatic drug; bDMARD, biological DMARD; sDMARD, synthetic DMARD.

\section{Assessment of postdiscontinuation treatment}

Based on the base case scenario (12-week gap, NP assessment 18 months after index date), $36.7 \%$ of the observed MTX-naive patients had discontinued their treatment. After discontinuation, 419 patients ( $94.4 \%$ of all NP patients) could be observed for a follow-up period of 12 months after the NP event. Of these, $39.9 \%$ restarted their MTX therapy (patients with/without at least one rheumatologist visit in the follow-up period: $43.8 / 36.2 \% ; P=0.070), 13.8 \%$ received another nonMTX sDMARD therapy (with/without rheumatologist visit: 15.4/12.4\%; $P=0.368), 8.1 \%$ received at least one bDMARD prescription (with/without rheumatologist visit: 12.4/4.1\%; $P=0.002)$ and $49.2 \%$ did not receive any DMARD prescription at all (with/without rheumatologist visit: 43.3/54.6\%; $P=0.021$ ).

\section{Assessment of treatment adherence}

The overall 12- and 24-month MPRs for MTX therapy in the analyzed MTX treatment-experienced RA patients were $83.0 \%$ and $76.5 \%$, respectively. The percentage of NA patients (MPR $<80 \%$ ) was $25.8 \%$ for the 12 -month follow-up and $33.8 \%$ for the 24-month follow-up (Table 4).

In our second adherence analysis, which was carried out during periods of general treatment continuation only (no gaps $>12$ weeks), mean MPRs were $94.7 \%$ (all patients), $95.0 \%$ (treatment-naive patients only), 94.8\% (MTX monotherapy), 94.5\% (MTX+other DMARD therapy), 93.7\% (MTX+bDMARD therapy), 96.0\% (oral MTX therapy), 91.6\% (subcutaneous MTX therapy) and $92.9 \%$ (change between oral and subcutaneous therapy). 
A

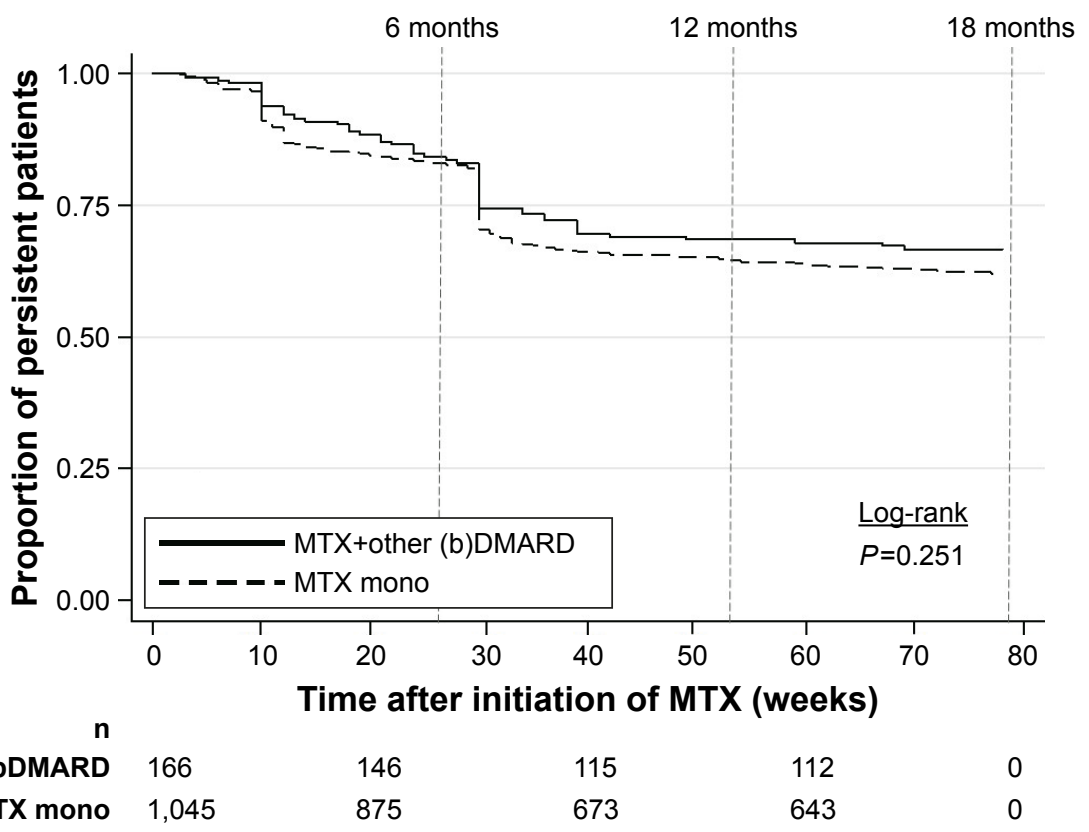

B

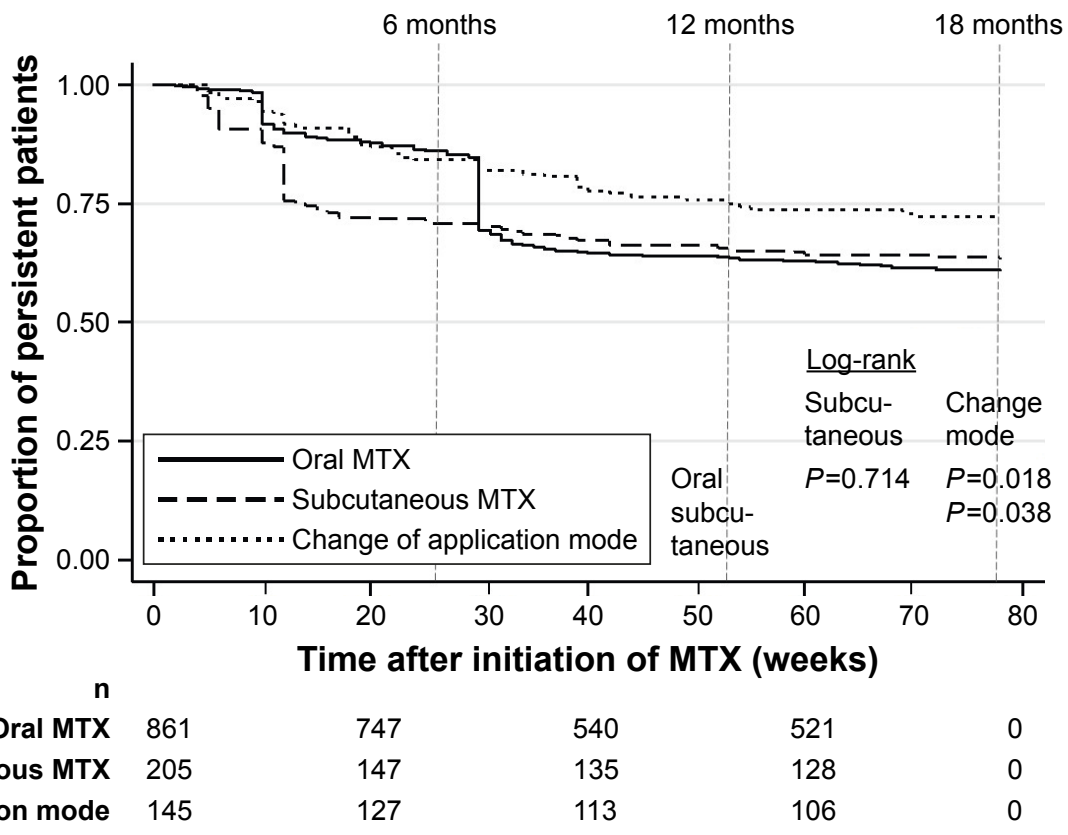

Figure 2 Kaplan-Meier curves for the percentage of RA MTX treatment-naive patients who persist with their MTX therapy during 18 months after therapy initiation. Notes: (A) Kaplan-Meier curves - MTX mono, MTX+other bDMARD. Kaplan-Meier curve for the percentage of RA MTX treatment-naive patients ( $\mathrm{n}=\mathrm{I}, 2 \mathrm{I} I$ ) who persist with their MTX therapy during 18 months after therapy initiation. The figure describes the percentage of RA patients who still persist with their newly started MTX therapy over time. This is described for two patient subgroups: RA patients who received MTX monotherapy versus patients who received another DMARD or bDMARD during the observational period. The difference in discontinuation rates between the groups was analyzed by means of a log-rank test. Censoring was conducted in case of death of a patient or in case of end of observational period, whatever came first. (B) Kaplan-Meier curves - oral MTX, subcutaneous MTX, change of application mode. Kaplan-Meier curve for the percentage of RA MTX treatment-naive patients $(n=I, 2 I I)$ who persist with their MTX therapy during 18 months after therapy initiation. The figure describes the percentage of RA patients who still persist with their newly started MTX therapy over time. This is described for the following patient subgroups: RA patients who received an oral MTX therapy only or a subcutaneous MTX therapy only and RA patients who experienced a change in application mode of MTX therapy (from oral to subcutaneous or vice versa). Differences in discontinuation rates between the groups were analyzed by means of log-rank tests. Censoring was conducted in case of death of a patient or in case of end of observational period, whatever came first.

Abbreviations: RA, rheumatoid arthritis; MTX, methotrexate; DMARD, disease-modifying antirheumatic drug; bDMARD, biological DMARD.

Table 4 shows the corresponding percentages of patients with MPR $<80 \%$ and the results of scenario analyses (MPR thresholds $70 \%$ or $90 \%$ ). The distribution of MPRs across our patient sample is shown in Figure S1.

\section{Discussion}

\section{Study objectives and main results}

Based on a German claims dataset, we aimed to assess the level of persistence and adherence to MTX therapy in RA 
Table 3 Results of medication - persistence analysis ( $n=I, 2$ II RA patients who started MTX therapy)

\begin{tabular}{|c|c|c|c|c|c|c|}
\hline & \multicolumn{6}{|c|}{ Treatment persistence } \\
\hline & $\begin{array}{l}\text { After } \\
6 \text { months }\end{array}$ & $\begin{array}{l}\text { After } \\
12 \text { months }\end{array}$ & $\begin{array}{l}\text { After } \\
18 \text { months }\end{array}$ & $\begin{array}{l}\text { After } \\
6 \text { months }\end{array}$ & $\begin{array}{l}\text { After } \\
12 \text { months }\end{array}$ & $\begin{array}{l}\text { After } \\
18 \text { months }\end{array}$ \\
\hline $\begin{array}{l}\text { NP definition: gap of at least } \\
12 \text { weeks/24 weeks }\end{array}$ & 12 weeks & 12 weeks & 12 weeks & 24 weeks & 24 weeks & 24 weeks \\
\hline $\begin{array}{l}\text { Percentage of all MTX treatment- } \\
\text { naive patients }(n=I, 2 I I) \text { who } \\
\text { discontinued MTX therapy }\end{array}$ & 16.7 & 34.0 & 36.7 & 11.2 & 25.1 & 26.5 \\
\hline $\begin{array}{l}\text { Mean time until } \\
\text { discontinuation of MTX } \\
\text { therapy for abovementioned } \\
\text { patients (median) }\end{array}$ & $\begin{array}{l}11.9 \text { weeks } \\
\text { (10 weeks) }\end{array}$ & $\begin{array}{l}22.2 \text { weeks } \\
(27 \text { weeks) }\end{array}$ & $\begin{array}{l}25.2 \text { weeks } \\
(30 \text { weeks) }\end{array}$ & $\begin{array}{l}\text { II.2 weeks } \\
\text { (10 weeks) }\end{array}$ & $\begin{array}{l}22.7 \text { weeks } \\
(30 \text { weeks) }\end{array}$ & $\begin{array}{l}24.8 \text { weeks } \\
\text { ( } 30 \text { weeks) }\end{array}$ \\
\hline $\begin{array}{l}\text { Estimated mean overall } \\
\text { treatment continuation time }{ }^{\mathrm{a}}\end{array}$ & 58.4 weeks & & & 63.7 weeks & & \\
\hline Percentage of following treatment- & patient subgr & who discontin & 1TX therapy: & & & \\
\hline MTX mono & 16.8 & 34.4 & 37.2 & 11.9 & 26.2 & 27.7 \\
\hline MTX+other DMARD & 14.3 & 29.5 & 31.4 & 7.6 & 17.1 & 18.1 \\
\hline MTX+bDMARD & 15.6 & 33.8 & 36.4 & 6.5 & 19.5 & 22.1 \\
\hline Oral MTX & 13.8 & 35.7 & 38.2 & 8.7 & 26.6 & 27.9 \\
\hline Subcutaneous MTX & 29.3 & 34.1 & 36.6 & 23.9 & 26.3 & 28.3 \\
\hline $\begin{array}{l}\text { Change in MTX } \\
\text { application mode }\end{array}$ & 15.9 & 24.1 & 27.6 & 8.3 & 14.5 & 15.9 \\
\hline
\end{tabular}

Notes: aEstimated survival time based on KM estimates. Note that the KM estimates did not represent the median survival time.

Abbreviations: NP, nonpersistence; MTX, methotrexate; DMARD, disease-modifying antirheumatic drug; bDMARD, biological DMARD; RA, rheumatoid arthritis; KM, Kaplan-Meier.

patients and to identify the treatment patterns of RA patients after discontinuation of MTX therapy.

The strength of this study is its use of a very large observational database. Additionally, we differentiated between treatment persistence and treatment adherence since we believe that these are different real-world phenomena that may be caused by different factors and may lead to different conclusions. For example, discontinuation of MTX therapy (NP) may be caused by patients' behavior, but it may also be based on a physician's decision not to prescribe MTX anymore because of severe safety concerns and/or treatment failure. NA, on the other hand, happens despite existing prescriptions of a treating physician and can be assumed to be caused mainly by patient-centered factors. ${ }^{15-17}$ However,

Table 4 Results of medication - adherence analysis (all RA patients who received MTX therapy)

\begin{tabular}{|c|c|c|c|}
\hline & $\begin{array}{l}\text { Base case: from first until last } \\
\text { observed MTX prescription or until } \\
\text { first day of an observed treatment gap } \\
\text { ( }>12 \text { weeks); whichever came first }\end{array}$ & $\begin{array}{l}\text { Scenario I: interval- } \\
\text { based calculation: } \\
\text { I } 2 \text { months since } \\
\text { index prescription }\end{array}$ & $\begin{array}{l}\text { Scenario } 2 \text { : interval- } \\
\text { based calculation: } \\
24 \text { months since } \\
\text { index prescription }\end{array}$ \\
\hline $\mathrm{N}$ & $6,104^{\mathrm{a}}$ & $7,146^{b}$ & $7,146^{c}$ \\
\hline Mean MPR (\%) (median) & $94.7^{\circ}(97.7)$ & $83.0(100.0)$ & $76.5(96.2)$ \\
\hline Percentage of patients with an MPR $<80 \%$ & 6.5 & 25.8 & 33.8 \\
\hline Percentage of patients with an MPR $<70 \%$ & 2.5 & 22.6 & 29.2 \\
\hline Percentage of patients with an MPR $<90 \%$ & 18.3 & 29.1 & 43.8 \\
\hline \multicolumn{4}{|c|}{ Percentage of following patient subgroups with an MPR $<80 \%$} \\
\hline - MTX treatment-naive patients & - 6.3 & - 41.8 & - 53.3 \\
\hline - MTX mono & $\bullet 6.8$ & - 23.6 & - 30.6 \\
\hline - MTX+other DMARD & - 6.8 & - 14.9 & - 23.8 \\
\hline - MTX+bDMARD & $\bullet 8.7$ & - 12.8 & - 22.9 \\
\hline - Oral MTX & - 5.1 & - 25.2 & - 32.7 \\
\hline - Subcutaneous MTX & - 12.1 & - 30.2 & - 40.2 \\
\hline - Change in MTX application mode & - 8.4 & - 19.2 & - 30.0 \\
\hline
\end{tabular}

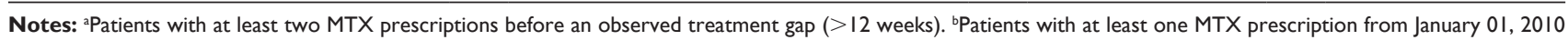
to December 31, 201I. 'Weighted MPR, based on length of observational period.

Abbreviations: MTX, methotrexate; MPR, medication possession ratio; DMARD, disease-modifying antirheumatic drug; bDMARD, biological DMARD; RA, rheumatoid arthritis. 
in most publications evaluated by the authors of this study, adherence and persistence are analyzed jointly, so that reported percentages of NA patients still include patients discontinuing their therapy during a predefined observational period. If, for example, and based on our database, the percentage of NA patients is calculated as MPR $<80 \%$ for a follow-up of 2 years irrespective of continuation/ discontinuation of therapy during that period, then $33.8 \%$ of the patients need to be classified as NA. However, most of these NA patients discontinued treatment instead of implementing their therapy in a suboptimal way. So, in our main analysis, the percentage of NA patients decreased to $6.5 \%$.

The only obvious disadvantage of our methodology in comparison to the more general MPR approach is that we may have underestimated NA for NP patients, because periods after a restart of MTX therapy, which is also potentially vulnerable to NA, were not included in our adherence analysis.

Our study, using a gap $>12$ weeks' threshold, revealed that $34.0 \%$ of MTX treatment-naive patients discontinued their MTX therapy after 12 months. Considering an additional 6 months and observing 18 months after therapy initiation, we found that only an additional $2.7 \%$ of MTX patients discontinued therapy. This may indicate that persistence is a critical issue at the beginning of that therapy. It is known from clinical studies that this may be explained by severe side effects/toxicity, by low therapy effectiveness in specific RA patients or by patient's decisions. ${ }^{18,19}$ The percentage of RA patients who poorly implemented MTX therapy, defined as NA associated with an MPR $<80 \%$ during periods of general MTX therapy discontinuation, was $6.5 \%$, indicating a rather good quality of therapy implementation during its general continuation.

So, early MTX therapy discontinuation seems to be the most critical issue, based on our observations. Whether an observed early noneffectiveness of therapy, severe side effects, a poor management of light side effects or even other reasons explain this therapy discontinuation was not explored in our study. If there would be potential for a more closer and better management of RA patients in their early phase of MTX treatment, this could both improve MTX therapy outcomes and could reduce the percentage of patients in need of therapy intensification, eg, with bDMARDs.

A systematic international review summarizing 35 articles (1985-2008) that addressed adherence to/persistence with DMARD treatment in RA patients (of these, 10 articles reported adherence rates) reported a percentage of 30-100 of RA patients to be adherent to DMARD therapy. ${ }^{6}$
The substantial difference in reported NA rates in these publications is mainly due to different methodologies used in the various analyses to measure adherence: these range from electronic event monitoring systems to pill counts, self-reports and claims data analyses.

Previous US claims data analyses reported numbers of NP patients similar to our analysis, if methodological differences are taken into account. ${ }^{20-23} \mathrm{In}$ line with that, a recent analysis of a Danish nationwide longitudinal cohort of patients hospitalized for RA reported a substantial percentage of $>10 \%$ of patients to be early MTX therapy discontinuers, defined as no second filled MTX prescription. ${ }^{24}$

However, we report a lower percentage of patients being nonadherent to MTX therapy. This is mainly because we analyzed adherence during periods of MTX treatment continuation only. If both persistence and adherence are analyzed jointly, nearly $40 \%$ of RA patients face either NP or NA, which is in accordance with previous publications, also in a comparison to other long-term chronic diseases. ${ }^{25-28}$

Due to the nature of our dataset, we were able to describe the drug treatment of RA patients after MTX therapy discontinuation. We showed that $39.9 \%$ of patients restarted MTX therapy after a gap $>12$ weeks and that follow-up prescriptions of another DMARD (13.8\%) or adding a bDMARD (as monotherapy or combination therapy; $8.1 \%$ ) were common. Nevertheless, a substantial percentage of patients $(49.2 \%)$ did not receive any DMARD treatment in the 12 months after MTX therapy discontinuation, which is not in line with treatment guidelines. ${ }^{5}$ One reason could be that our patients started MTX therapy but were misdiagnosed with RA. Due to the nature of our dataset, we could not assess in which percentage of NP patients this was the case.

Additionally, we found that the percentage of NP patients who did not receive any DMARD follow-up treatment was substantially higher in patients who did not visit a rheumatologist in the year after MTX discontinuation. This was the case in $52.0 \%$ of our observed patients who discontinued MTX therapy.

\section{Limitations}

We acknowledge some limitations of our analysis. Due to longitudinal limitations of our dataset at the time of analyses, we could only observe 24 months after the start of MTX therapy. Further research is needed to describe longer term persistence/adherence in RA patients who started MTX therapy. In addition to that, generally, we did not explore any causes of NP or NA to MTX therapy in our study because of lack of data. 
We defined NP as a treatment gap $>12$ weeks and NA as an MPR $<80 \%$. While these thresholds are widely used in general adherence/persistence literature and in claims data analyses addressing RA patients, they have so far hardly been clinically validated. ${ }^{22,29} \mathrm{We}$ dealt with this weakness by reporting results of a sensitivity analysis using a gap $>24$ weeks as NP definition and by using different MPR thresholds of $70 \%, 80 \%$ and $90 \%$.

Finally, we only analyzed filled prescriptions in our database. We may have underestimated NA and NP because specific patients may have filled prescriptions but did not take them as prescribed.

\section{Conclusion and implications for practice}

NP to MTX treatment appears to be common in one-fourth of German patients with RA. An additional percentage of at least $6.5 \%$ of patients is also affected by NA. A considerable percentage of RA patients discontinuing MTX therapy do not receive any follow-up DMARD therapy. Consequently, efforts should be taken to increase the percentage of RA patients receiving DMARD treatment in accordance with guidelines.

\section{Key messages}

- One-fourth of German patients with RA are NP to MTX therapy.

- $6.5 \%$ of NP patients are also NA to MTX therapy.

- $50 \%$ of NP patients do not receive any follow-up DMARD treatment.

\section{Acknowledgments}

The authors would like to thank Dirk Ahilger, Michael Schoettler and Antje Groth for their valuable support during the manuscript preparation. This work was financially supported by Roche Pharma AG and Chugai Pharma Europe Ltd. German Branch. In view of German data protection law (SGB X), the authors are not allowed to distribute the analyzed dataset. Individuals interested in the dataset are invited to send an application to the dataset owner (AOK PLUS; Dr Ulf Maywald, ulfdr.maywald@plus.aok.de).

\section{Author contributions}

Specifically, the main tasks the authors engaged in were TW, project lead, contributed to writing all parts of the article. SM contributed to statistical analysis and validation of database. $\mathrm{UM} / \mathrm{AF}$ contributed to statistical analysis and interpretation of results in discussion section. J-PF, HH and KK contributed to conception/design of the study and interpretation of results in discussion section. All authors contributed toward data analysis, drafting and revising the paper and agree to be accountable for all aspects of the work.

\section{Disclosure}

TW has received honoraria from several pharmaceutical/ consultancy companies (Novo Nordisk, Abbvie, Merck, GSK, BMS, LEO Pharma, Astra Zeneca, Bayer, Boehringer Ingelheim, Pharmerit). SM participated in this study as a staff member of IPAM; IPAM work in this study was sponsored by Roche Pharma AG and Chugai Pharma Europe Ltd, Germany. AF conducted consultancies for Bayer Pharma AG in 2016 and is employed by AOK PLUS. UM does not have any conflicts of interest except those potentially related to his employer, AOK PLUS. KK has received honoraria as a member of advisory boards and/or speakers bureau from: Abbvie, BMS, Medac, MSD, Pfizer, Roche and UCB. J-PF and $\mathrm{HH}$ are employed by Roche Pharma AG and Chugai Pharma Europe Ltd, German branch. The authors report no other conflicts of interest in this work.

\section{References}

1. Scott DL, Wolfe F, Huizinga TWJ. Rheumatoid arthritis. Lancet. 2010;376(9746):1094-1108.

2. Humphreys JH, Verstappen SMM, Hyrich KL, Chipping JR, Marshall T, Symmons DPM. The incidence of rheumatoid arthritis in the UK: comparisons using the 2010 ACR/EULAR classification criteria and the 1987 ACR classification criteria. Results from the Norfolk Arthritis Register. Ann Rheum Dis. 2013;72(8):1315-1320.

3. Kapetanovic MC, Lindqvist E, Nilsson J-A, Geborek P, Saxne T, Eberhardt K. Development of functional impairment and disability in rheumatoid arthritis patients followed for 20 years: relation to disease activity, joint damage, and comorbidity. Arthritis Care Res (Hoboken). 2015; 67(3):340-348.

4. Elliott RA, Shinogle JA, Peele P, Bhosle M, Hughes DA. Understanding medication compliance and persistence from an economics perspective. Value Health. 2008;11(4):600-610.

5. Smolen JS, Landewé R, Breedveld FC, et al. EULAR recommendations for the management of rheumatoid arthritis with synthetic and biological disease-modifying antirheumatic drugs: 2013 update. Ann Rheum Dis. 2014;73(3):492-509.

6. Salt E, Frazier SK. Adherence to disease-modifying antirheumatic drugs in patients with rheumatoid arthritis. Orthop Nurs. 2010;29(4):260-275.

7. Radner H, Yoshida K, Hmamouchi I, Dougados M, Smolen JS, Solomon DH. Treatment patterns of multimorbid patients with rheumatoid arthritis: results from an international cross-sectional study. J Rheumatol. 2015;42(7):1099-1104.

8. Lopez-Gonzalez R, Leon L, Loza E, Redondo M, Garcia de Yebenes MJ, Carmona L. Adherence to biologic therapies and associated factors in rheumatoid arthritis, spondyloarthritis and psoriatic arthritis: a systematic literature review. Clin Exp Rheumatol. 2015;33(4):559-569.

9. Emery P. Treatment of rheumatoid arthritis. BMJ. 2006;332(7534): $152-155$.

10. Smolen JS, Aletaha D, Bijlsma JWJ, et al. Treating rheumatoid arthritis to target: recommendations of an international task force. Ann Rheum Dis. 2010;69(4):631-637.

11. Blum MA, Koo D, Doshi JA. Measurement and rates of persistence with and adherence to biologics for rheumatoid arthritis: a systematic review. Clin Ther. 2011;33(7):901-913. 
12. Federal Data Protection Act. Federal Data Protection Act in the version promulgated on 14 January 2003 (Federal Law Gazette I p. 66), as most recently amended by Article 1 of the Act of 14 August 2009 (Federal Law Gazette I p. 2814). Available from: https://www.gesetzeim-internet.de/englisch_bdsg/englisch_bdsg.pdf. Accessed May 25, 2017.

13. Working Group for the Survey and Utilization of Secondary Data (AGENS); Working Group for Epidemiological Methods. GPS Good Practice in Secondary Data Analysis: Revision after Fundamental Reworking. 2008. Available from: http://dgepi.de/fileadmin/ pdf/leitlinien/gps-version2-final_ENG.pdf. Accessed May 25, 2017.

14. Bundesverband der Pharmazeutischen Industrie e.V., Institut für Pharmakoökonomie und Arzneimittellogistik e.V. Leitfaden zur Planung von Versorgungsforschungsstudien in pharmazeutischen Unternehmen. Berlin; 2015.

15. Pasma A, van't Spijker A, Hazes JMW, Busschbach JJV, Luime JJ. Factors associated with adherence to pharmaceutical treatment for rheumatoid arthritis patients: a systematic review. Semin Arthritis Rheum. 2013;43(1):18-28.

16. Zeber JE, Manias E, Williams AF, et al. A systematic literature review of psychosocial and behavioral factors associated with initial medication adherence: a report of the ISPOR medication adherence \& persistence special interest group. Value Health. 2013;16(5): 891-900.

17. Wilke T, Muller S, Morisky DE. Toward identifying the causes and combinations of causes increasing the risks of nonadherence to medical regimens: combined results of two German self-report surveys. Value Health. 2011;14(8):1092-1100.

18. Katchamart W, Trudeau J, Phumethum V, Bombardier C. Methotrexate monotherapy versus methotrexate combination therapy with non-biologic disease modifying anti-rheumatic drugs for rheumatoid arthritis. Cochrane Database Syst Rev. 2010;4:CD008495.

19. Grigor C, Capell H, Stirling A, et al. Effect of a treatment strategy of tight control for rheumatoid arthritis (the TICORA study): a single-blind randomised controlled trial. Lancet. 2004;364(9430):263-269.
20. Grijalva CG, Kaltenbach L, Arbogast PG, Mitchel EF, Griffin MR Adherence to disease-modifying antirheumatic drugs and the effects of exposure misclassification on the risk of hospital admission. Arthritis Care Res. 2010;62(5):730-734.

21. Harley CR, Frytak JR, Tandon N. Treatment compliance and dosage administration among rheumatoid arthritis patients receiving infliximab, etanercept, or methotrexate. Am J Manag Care. 2003;9(6 suppl): S136-S143.

22. Cannon GW, Mikuls TR, Hayden CL, et al. Merging Veterans Affairs rheumatoid arthritis registry and pharmacy data to assess methotrexate adherence and disease activity in clinical practice. Arthritis Care Res (Hoboken). 2011;63(12):1680-1690.

23. Tang B, Rahman M, Waters HC, Callegari P. Treatment persistence with adalimumab, etanercept, or infliximab in combination with methotrexate and the effects on health care costs in patients with rheumatoid arthritis. Clin Ther. 2008;30(7):1375-1384.

24. Bliddal H, Eriksen SA, Christensen R, et al. Adherence to methotrexate in rheumatoid arthritis: a Danish nationwide cohort study. Arthritis. 2015;2015:915142.

25. Belinchon I, Rivera R, Blanch C, Comellas M, Lizan L. Adherence, satisfaction and preferences for treatment in patients with psoriasis in the European Union: a systematic review of the literature. Patient Prefer Adherence. 2016;10:2357-2367.

26. Polonsky WH, Henry RR. Poor medication adherence in type 2 diabetes: recognizing the scope of the problem and its key contributors. Patient Prefer Adherence. 2016;10:1299-1307.

27. Moon Z, Moss-Morris R, Hunter MS, Carlisle S, Hughes LD. Barriers and facilitators of adjuvant hormone therapy adherence and persistence in women with breast cancer: a systematic review. Patient Prefer Adherence. 2017;11:305-322.

28. Testa A, Castiglione F, Nardone OM, Colombo GL. Adherence in ulcerative colitis: an overview. Patient Prefer Adherence. 2017;11: 297-303.

29. Wilke T, Groth A, Mueller S, et al. How to use pharmacy claims data to measure patient nonadherence? The example of oral diabetics in therapy of type 2 diabetes mellitus. Eur J Health Econ. 2013;14(3):551-568. 


\section{Supplementary material}

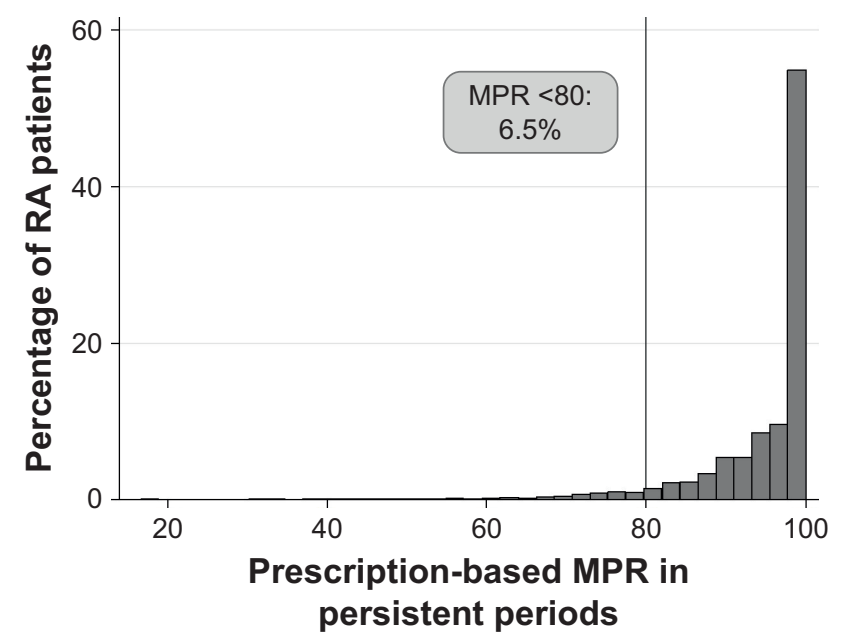

Figure SI Distribution of MPR among RA patients who received MTX therapy

Notes: The figure shows the distribution of patient-specific MPRs in the sample of RA patients who received MTX therapy. MPR was calculated during periods of therapy continuation only. So, our analysis was carried out from the first observed MTX prescription until the last observed MTX prescription. In case an MTX treatment gap was observed ( $>12$ weeks), observation ended with the date of the last prescription before that observed gap.

Abbreviations: MPR, medication possession ratio; RA, rheumatoid arthritis; MTX, methotrexate.

\section{Publish your work in this journal}

Patient Preference and Adherence is an international, peer-reviewed, open access journal that focuses on the growing importance of patient preference and adherence throughout the therapeutic continuum. Patient satisfaction, acceptability, quality of life, compliance, persistence and their role in developing new therapeutic modalities and compounds to optimize clinical outcomes for existing disease states are major areas of interest for the journal. This journal has been accepted for indexing on PubMed Central The manuscript management system is completely online and includes a very quick and fair peer-review system, which is all easy to use. Visit http://www. dovepress.com/testimonials.php to read real quotes from published authors. 